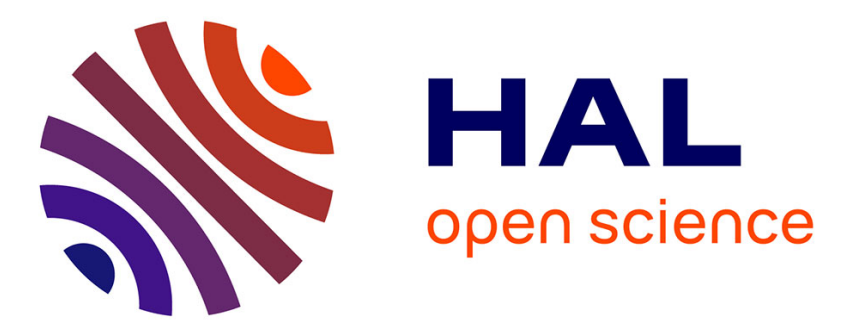

\title{
Making Land Use - Transport models operational tools for planning: from a top-down to an end-user approach
} Mathieu Saujot, Matthieu de Lapparent, Élise Arnaud, Emmanuel Prados

\section{To cite this version:}

Mathieu Saujot, Matthieu de Lapparent, Élise Arnaud, Emmanuel Prados. Making Land Use - Transport models operational tools for planning: from a top-down to an end-user approach. Transport Policy, 2016, 49, pp.20 - 29. 10.1016/j.tranpol.2016.03.005 . hal-01402863

\section{HAL Id: hal-01402863 \\ https://hal.inria.fr/hal-01402863}

Submitted on 25 Nov 2016

HAL is a multi-disciplinary open access archive for the deposit and dissemination of scientific research documents, whether they are published or not. The documents may come from teaching and research institutions in France or abroad, or from public or private research centers.
L'archive ouverte pluridisciplinaire HAL, est destinée au dépôt et à la diffusion de documents scientifiques de niveau recherche, publiés ou non, émanant des établissements d'enseignement et de recherche français ou étrangers, des laboratoires publics ou privés. 


\title{
Making Land Use - Transport models operational tools for planning: from a top-down to an end-user approach.
}

\author{
Mathieu Saujot ${ }^{a}$, Matthieu de Lapparent ${ }^{b}$, Elise Arnaud ${ }^{c}$, Emmanuel Prados ${ }^{d}$ \\ a IDDRI - SciencesPo, Paris, France \\ b EPFL, ENAC, TRANSP-OR, Switzerland \\ c INRIA, UGA, CNRS-LJK, France \\ d INRIA, UGA, CNRS-LJK, France
}

\begin{abstract}
Land Use and Transport Integrated models (LUTIs) are promising approaches for urban planning. There is large literature describing their technical architectures or using them in various scientific contexts. Yet little attention has been paid to expectations of practitioners (planners) and to the operational use of such models. The gap between lab application and operational use for planning practice is still to be filled. We shed light on what would make them definitely accepted and more used by planners to evaluate a range of urban and transport policies. In addition to literature review and our own experience dealing with urban planning agencies, we have interviewed different types of end users in France to identify their motivations and barriers to use LUTI models. The results show demand for a far more bottom-up oriented approach: the models should consider objectives and general needs of end users to live up to their expectations. Only a closer collaboration between modelers and end users, and more efforts to integrate modeling into urban planning, will make LUTIs considered as relevant approaches.
\end{abstract}

Key words: Land Use and Transport Integrated models; Planning support system, Planning practice

\section{Highlights:}

- A gap between theory and practice has to be filled for LUTI modeling.

- This effort to make LUTI operational tools is more critical than technical improvements.

- Academics should build up on more bottom-up approaches, based on end-users expectations and resources.

- Calibration and validation procedures should be harmonized, improved and adapted to specific LUTI use. 


\section{Introduction}

This article aims at improving the understanding of conditions under which Land Use and Transport Integrated models (LUTIS) would be accepted and used by planners and practitioners. We conducted a qualitative survey among French practitioners about their experience and expectations regarding LUTI modeling, in order to complete and support our reflection based on the literature and our own experience as modelers. The rationale behind the survey is: to make clear the requirements on LUTI models from an end-user perspective; to understand to which extent such models may complement other planning approaches from an empirical standpoint ; to help organizing fruitful top-down and bottom-up relations between LUTI developers and end-users.

A large literature is dedicated to these models. Contrary to classical and widely used traffic models, which consider the urban structure as an exogenous input to simulate the mobility system, LUTIs simulate both the land use system and the transport system, as well as their interactions. All LUTI models represent the evolution of different markets (land, housing, transport, labor) but differ in terms of modelling theories and methods, e.g. aggregated or agent based, based on market equilibrium or dynamic processes (Jin and Wegener, 2013). Some articles present their main features and propose a review and a classification (Simmonds et al., 1999; Wegener, 1994; Wegener, 2004; Batty, 2009; lacono et al., 2008). Others present the existing models in line with different frameworks (Hunt et al., 2005; Silva and Wu, 2012), their application to territories (Feldman et al., 2009; Lautso et al., 2004; Gayda et al., 2005; Sustaincity, 2013) or their historical development (Simmonds and Feldman, 2007). Theoretical issues are also debated, Jin and Wegener (2013) and Anas (2013) for example discuss equilibrium and the evolution towards more dynamic modeling. Other articles compare applications of different models (Hunt et al., 2001).

This literature has been useful to develop and improve modeling principles and illustrates what we can theoretically expect from the models to inform policymakers. However it says little about the frequency of their use, their maturity for operational use and their potential impacts for planning and decision making. The discussion is generally oriented towards technical and theoretical features, and the question whether the model can support an actual planning decision is poorly considered. In other words, the main question addressed is how these models are representing the different aspects of urban systems, including a discussion on the advantages and limits of each modeling solution, based on theoretical analysis. Hunt et al. (2005) for example aim at providing with a more practical evaluation of the current modeling framework as a guide to practitioners. Yet, they mainly focus on the formal characteristics of the modeling frameworks and the way they represent the different dimensions of urban systems. A concrete discussion on how these models were used and 
on the practical difficulties of modeling is missing and the suggested improvements are not taken from practice but from an ideal model.

Generally, applications are presented as evidence that the model is a useful tool, but they rarely take the planners' practical needs into account. As observed by Vonk et al. (2005) and Wegener (2011), the Planning Support System (PSS) and LUTI modeling community is often focused on academic issues, with a "strong emphasis on the supply side" (Vonk et al., 2005, p. 1) and a lesser concern to investigate the practical and operational use of models by practitioners.

Whether these models can be operational and under which conditions they can improve planning methodologies and policy design are important issues that must be discussed in detail. Originally the objectives of LUTIs were twofold (Batty, 1979; Batty, 2009; Klosterman, 2012; Lee, 1994):

1) improve, develop and test a theory for urban systems;

2) improve policy design and planning methodologies;

We still lack research on the latter. Even if some elements are available based on the experience of planners, researchers (Lee, 1973; Lee, 1994; Klosterman, 2012), or modelers (Waddell, 2011; Timmermans and Arentze, 2011), this discussion is only occasionally the main purpose of the article and rarely based on a dedicated methodology.

Lee $(1973,1994)$ was one of the first to discuss LUTIs from an operational planning view, pointing out the inherent difficulty of using complex modeling tools to feed a decision making process. Klosterman (1994a, 1994b) and Wegener (1994) also highlighted this point. Wegener (2011) discussed the disaggregation trend in modeling and the technical difficulties of using microsimulation modeling in planning. Waddell (2011) described the many challenges - technical and nontechnical - of transferring modeling tools from academic research to planning agencies, and explained what has been undertaken for Urbansim development to increase the appropriation by end users. Timmermans and Arentze (2011), inspired by their own experience of modeling, analyzed the links between research and urban planning. Klosterman (2012) discussed the nature of modeling, using the simple/complex model opposition.

Noteworthy contributions also come from the PSS literature, even though they are not focused primarily on LUTIs. Vonk et al. (2005) investigate the bottlenecks blocking a wide usage of PSS (including LUTIs and other tools) with a survey of people involved in PSS (mainly academics and researchers). This paper incited us to use a similar approach specific to LUTIs, with more details on 
the use of the model and a focus on local authorities. Brömmelstroet and Bertolini (2008) shed light on obstacles that explain low levels of use. They also explore the planning process to understand which type of methods and tools would best fit as a planning support. They clearly show the necessity to connect end users (State transport services, local transport authorities, planning agencies, consultancies) and modelers through specific procedures and tools. Based on the "knowledge use" literature, Gudmunsson (2011) provides a framework for understanding the gap between transport modeling efforts and planning needs, and potential ways to diminish this gap. He underlines the need to carefully match policy expectations with the outputs the model can provide. Other works worth noting are Still et al. (1999) and Ewing and Bartholomew (2009) who address the practical use of LUTIs with an assessment of the different methodologies used to inform planning.

As highlighted by Klosterman (2012, p. 1), modeling "reflects more fundamental assumptions about the limits of science, the role of the public, and the nature of planning", and requires thinking in terms of policy making and not only in terms of technical issues. Although LUTIs greatly improved during the last two decades, they are not yet widely disseminated. End users still seem indecisive about using them. As a result, they are primarily considered as research objects. The gap between lab application and operational use for planning practice is still to be filled (Wegener, 2011; Silva and Wu, 2012; Brömmelstroet and Bertolini, 2008; Aashto, 2007; Nguyen-Luong, 2012). Thus we still need to better understand how LUTIs are currently used, the barriers to their practical use and how they could better inform planning decisions and transport policies in practice. Doing so should help us identify the priorities for a LUTI agenda.

The rest of the paper is organized as follows. Section 2 defines our overall methodology. In the third section, we describe the current level of LUTI's practical use in France as well as in Europe and in the United States. In the fourth section, we specify the different purposes of using a LUTI and the type of the expected value added. The fifth section addresses the obstacles facing practical LUTI use and suggests some ways to overcome these difficulties. We draw our conclusions in the last section.

\section{Overall methodology}

A survey with 20 questions about urban modeling practice and demand for LUTI models was prepared. Hardy's survey (Hardy, 2011) $)^{1}$ was used as a basis for several questions, and has been

\footnotetext{
${ }^{1}$ Hardy developed it for US practitioners from the American Association of State Highway and Transportation
} 
adapted to our own purpose. Our survey was sent to 30 French modeling practitioners $^{2}$ (mainly in transport field) between summer and autumn 2013. We received answers from 15 of them. They constitute a representative panel of the types of relevant stakeholders (consultancies, State departments, local authorities and planning agencies). To improve the quality of the survey and facilitate the process, the sample was targeted in this way: 1) a good level of modeling and the possible presence of innovation; 2) a diversity of actors; 3 ) when possible, existing contacts with researchers of the CITIES project consortium ${ }^{3}$. Of course, this strategy ${ }^{4}$ may introduce a bias, for example, toward an overestimation of the interest that LUTIs represent for the whole planning community, because we speak with transport modelers. Yet this does not necessarily mean that they are proponents of LUTI modelling. In any case, the results of the survey should be at least representative of the group of stakeholders who are real potential users in the medium term. The composition of the panel was: 5 transport authorities, 3 representatives of the State at the local level, 4 consultancies, 3 public planning organizations.

A survey description is given in the appendix. Analysis of the survey was twofold: qualitative analysis of the open-ended questions and percentages on the answers among respondents for the other questions ${ }^{5}$. Open-ended questions were used to evaluate the maturity of the organization in terms of modelling: dependence on consultancies, state of advancement on transport modelling. It helped us to confirm that the sample is composed of organizations with enough experience in terms of transport modelling to begin considering LUTI modelling. It also confirms our own experience i.e that specialized consultancies are crucial since public organizations do not have sufficient staff (both in

Officials and the Association of Metropolitan Planning Organizations. The purpose was to explore the "role that a simpler transportation and land use modeling approach can play to support decision-making within metropolitan planning" (Hardy, 2011).

2 The 30 French modelling practitioners were chosen all over France. We chose the most advanced organizations in terms of modelling, i.e those with the biggest likelihood to have an understanding and opinion about LUTI modelling, which is useful for our research.

${ }^{3}$ The CITIES project's ambition is to foster the use of LUTI, by developing methodologies and tools to facilitate their use (mainly numerical methods to help calibration and validation). The consortium includes mathematicians and computer scientists, most of French LUTI modeling teams and end users (planning agencies). Different LUTI are used (Urbansim, TRANUS, Pirandello). The project is financed by the French research agency (ANR).

${ }^{4}$ Via the choice of the interviewees (of whom a large part have connections with the researchers) but also because of the survey principle itself (where people who feel more concerned by the object of interest are more willing to answer).

${ }^{5}$ The percentage is computed by taking into account all the answers. 
terms of competences and quantity).

In order to complete the results of the survey, we also conducted 8 qualitative interviews with key actors of transport at the French national and local level: a high level expert of the ministry of sustainable development, a modeler from French national railway network (RFF), the chief economist of the Société du Grand Paris (SGP), modelers from île-de-France urban transport authority (STIF) and Greater Lyon area, and three consultancies. These interviews helped us to understand the maturity level of LUTI modeling and the conditions for LUTI diffusion.

By combining experience of the project consortium in implementing LUTI models, the survey and the interviews, we assume that we have a representative view of the French context. This study is completed by a review of the scientific literature that feeds our reflection and extends the work outside France.

\section{Useful LUTIs but are they used?}

\subsection{United States and Europe}

As stated earlier, a gap between research and practice exist in Europe and in the US ${ }^{6}$. As stated in lacono et al. (2008, p. 15): "Most of the newer generations of microsimulation models are designed with the objective of making them more policy sensitive. Unfortunately, few of them have yet reached a point where they can be fairly evaluated on this criterion". In a recent survey in the US, Lee (2009) shows that 47\% of Metropolitan Planning Organisations (MPO) of more than 200000 inhabitants are doing both transport and land use modeling. $46 \%$ of them use transport-only models. $47 \%$ use transport and land use models, but only $28 \%$ carries out an integrated planning (mostly using Urbansim, Pecas, Delta, Cube Land). The remaining 7\% do not use any kind of modelling tool. Other tools are based on graphical interfaces, ad hoc home applications, qualitative tools, etc. Hardy (2011, p. 122) observed that complex tools like LUTIs are not accessible to many planning agencies in the US, and that "The current literature is not clear as to what role computer modeling tools can have in the context of metropolitan planning in the U.S". Ewing and Bartholomew (2009) observed that methodologies are yet neither stabilized nor standardized in the US: in particular it is clear that the use of models is not automatic and that expert panels are still involved. Apart from the UK, which

\footnotetext{
${ }^{6}$ This choice was made because these areas correspond to most of the literature for this question, as well as to our own experience. Future works could fruitfully investigate other continents and especially South America where many LUTIs were developed.
} 
seems to be a place where LUTIs are the most commonly used for planning (May et al., 2008), LUTI modeling does not seem more developed in Europe. We do however highlight the recent Sustaincity project $^{7}$ that contributed to the development of LUTI models and helped increase their popularity in Europe.

\subsection{French context}

Operational use of LUTIs for the simulation of regional planning policies is still an exception in France, despite important research investments and recent interest of planning agencies. LUTIs have only been developed for research projects since the mid 2000's: Urbansim (Nicolas et al., 2009; NguyenLuong, 2008, Bonnafous et al., 2011); TRANUS (Saujot, 2013); and Pirandello (Delons et al., 2008). To date, no French local authority for planning or transport has appropriated the LUTI developed by academics specifically on its own territory, or developed its own LUTI.

In fact, the only example of an operational use of a LUTI is the Grand Paris project ${ }^{8}$, undertaken by the "Société du Grand Paris" (SGP).The Grand Paris project is the most important urban project in France, with a $€ 30$ billion investment in the next 20 years, mainly for new transport infrastructures. The SGP is in charge of the socio-economic impact assessment and they have constructed an ambitious program around LUTIs. A scientific committee has been set up to assess the modeling work done in parallel by three teams, each with a different tool (Relu-Tran, Urbansim, Pirandello). After four years, work is in process, but preliminary results show that using LUTIs for an operational project is much more difficult and time-consuming than expected. Moreover the data collection task was under-estimated and the question of the relevant scale of zoning was a permanent debate. It is difficult for the experts of SGP to obtain satisfying answers about the results and behavior of the models, and reciprocally it is difficult for modelers to explain precisely the differences between the respective models' results for a given scenario. This example shows clearly that even with an important budget and a high level of expertise, using LUTIs to help decision making for a project like the Grand Paris is very difficult. Although this kind of project helps LUTI modeling gain in maturity, LUTI modeling is not mature enough for practical use at least in France. Nevertheless, despite the difficulties and the non-legal obligation to evaluate spatial effects, the SGP still considers that it is essential to continue to develop LUTIs for broader socio-economic evaluation in planning and sustains its efforts.

\footnotetext{
${ }^{7}$ FP7 project funded by European Union: http://www.sustaincity.org

${ }^{8}$ http://www.societedugrandparis.fr/english
} 
Another meaningful example can be drawn from the experience of the Greater Lyon ${ }^{9}$. A consortium of 5 local actors was created to set up a new common transport model (region, department, State at the regional level, Great Lyon, local transport authority), with an important budget. Formerly, each actor had its own transport model. Their decision to use modeling for local decision making via such a collective platform was innovative, all the more that modeling was not so popular few years ago in this area. They considered the possibility of using a LUTI instead of a classical 4-steps transport model but concluded that it was not the right choice for three reasons: a lack of appropriate guidelines for LUTI implementation; insufficient expertise both inside and outside the consortium to ensure a good choice of a model, and high risk relative to a long and uncertain process of building the model.

As far as the consulting firms specialized in transport modeling in France are concerned, no ready-touse commercial LUTI package is available at this point. The market situation (low visibility in terms of demand, financial constraints and short implementation periods) makes it difficult for consultancies to develop their own models. This pushes some firms to think that LUTIs are not well adapted to current public demand. For others, it reinforces the need to find a strict trade-off between quality and simplicity of the LUTIs. Beyond the model, the general diffusion of LUTIs diffusion would require the development of national guidelines. Such guidelines exist for conventional transport modeling but not for LUTIs, and the scientific literature is generally of little assistance for end users. Finally, not all consulting firms have the same level of trust in the robustness of LUTIs.

\section{Different expectations about LUTIs when used for policy design}

As mentioned previously, there are two potential benefits of urban modeling: one for science, to deepen our understanding of complex interactions but also to test and produce new theories, and the other for policy making and to design operational policies (e.g. Klosterman, 2012; lacono et al, 2008; Batty, 1979; Lee, 1994), including a variety of prospective exercises (Banister and Hickman, 2013). These two fields are not uncoordinated as the development of new tools is often aiming at both objectives. But with the increasing complexity of models, the most advanced tools are yet far from simple operational use and policy design. Thus the real purpose of modeling is not always clear, even when a LUTI is used in a policy design project. For example, as observed by Lee (1994) there is often an ambiguity between tactical and strategic use. In broad outline, strategic use means use of a LUTI model to evaluate long-run planning options without looking for very detailed outcomes.

\footnotetext{
${ }^{9}$ Second largest agglomeration in France.
} 
Tactical use means use of a LUTI to detail and make short-run planning choices. Ambiguity comes from the fact that strategic and tactical planning are closely connected and that current development of LUTI models strive to do both at the same time.

To help policy design, we need to better understand how a LUTI can be used, i.e. which outputs can be provided, and in which step of the decision making.

\subsection{Policy design: which outputs?}

Our survey shows that, for French stakeholders, it is important to take into account transport and land use in an integrated way, and modeling tools are an interesting way to do so. Alongside other methods and types of analysis, modeling tools are considered important to evaluate or design land use and transport policies.

Another key lesson from our survey and interviews is that end users have very heterogenous expectations about LUTIs. Several objectives of LUTI modeling can be found among the different projects and actors:

- To make the spatial distribution of jobs and population/households endogenous (potential use by transport authority);

- To simulate effects of transport on land use (Nguyen-Luong, 2008);

- To evaluate effects of transport on land and housing prices (when data and models will be enough integrated to provide such outputs at a very detailed geographical scale);

- To assess environmental, social and economic impacts of urban dynamics and urban development scenarios (Nicolas et al., 2009; Saujot, 2013);

- To test and recommend land use and transport policies to mitigate urban sprawl or improve sustainability (Gayda et al., 2005; Lautso et al., 2004);

- To perform an overall cost-benefit analysis of a transport project, accounting for wider economic benefits;

- To present projects and discuss them with stakeholders, LUTIs being used as a support for the debate and participatory process.

Such a large spectrum of objectives has the following implications. First, users' requirements for LUTI modeling are more extensive than for travel demand modeling and traffic simulation. It actually superimposes land use modeling and related planning problems to the latter. This clearly makes the development of a commercial offer more complex since the demand is not precisely defined and may 
strongly vary from one case to another. Second, when presenting and judging a LUTI and its application, one should always refer to the specific outcome(s) that are expected from the model and show consistency between the objectives of the application and the structure of the model. Third, it has implications for calibration and validation goals and procedures.

\subsection{Policy design: which step of the decision making?}

It is not enough to define the expected outputs. We also need to specify the step of planning targeted by the use of a LUTI, and the way its outputs could be used by end users in the decision making process. The fundamental goal is to adjust the models to their role in the policy making process, as underlined by Vickerman (2008). Indeed, both PSS literature (Gudmundsson, 2011; Brommelstroet and Bertolini, 2008; Klosterman 2001) and science-policy interface literature (Sager and Ravlum, 2005; Vechionne, 2012) reveal the complexity of the link between modeling tools and decision-making process. As stated by Nilsson et al. $(2008$, p. 3), "more than three decades of policy analytic research remind us that the inter-relationship between assessment tools, the evidence they reveal, and their use by policy makers is unlikely to be straightforward".

As in Hardy (2011), in our survey, we proposed different steps of policy design where LUTIs could be used: 1) Exploration of planning possibilities and different strategies 2) Debate around scenarios and consultation with stakeholders 3) Strategic analysis of different scenarios and policies 4) Tactical assessment (design of projects). This 4 step representation is a strong simplification of the real planning process but remains useful to understand the role of LUTIs. Moreover each step requires a different prospective method, as described by Banister and Hickman (2013).

As shown in Fig. $1^{10}$, respondents of the survey consider LUTIs as useful tools to explore possibilities and strategies (1. and 3.) for the next 20-30 years, at an aggregated level (urban area). Tactical assessment and support for debate appear to be less important. Moreover, the survey reveals that the use of a LUTI would be most helpful in the process of defining the strategic urban planning document at the level of an urban area, which is coherent with the precedent answers. This is illustrated in Fig. 2.

\footnotetext{
${ }^{10}$ We are cognizant that this small sample is not enough to produce reliable statistics, and should rather be seen as a way to draw some trends, useful to complete and support our reflection.
} 


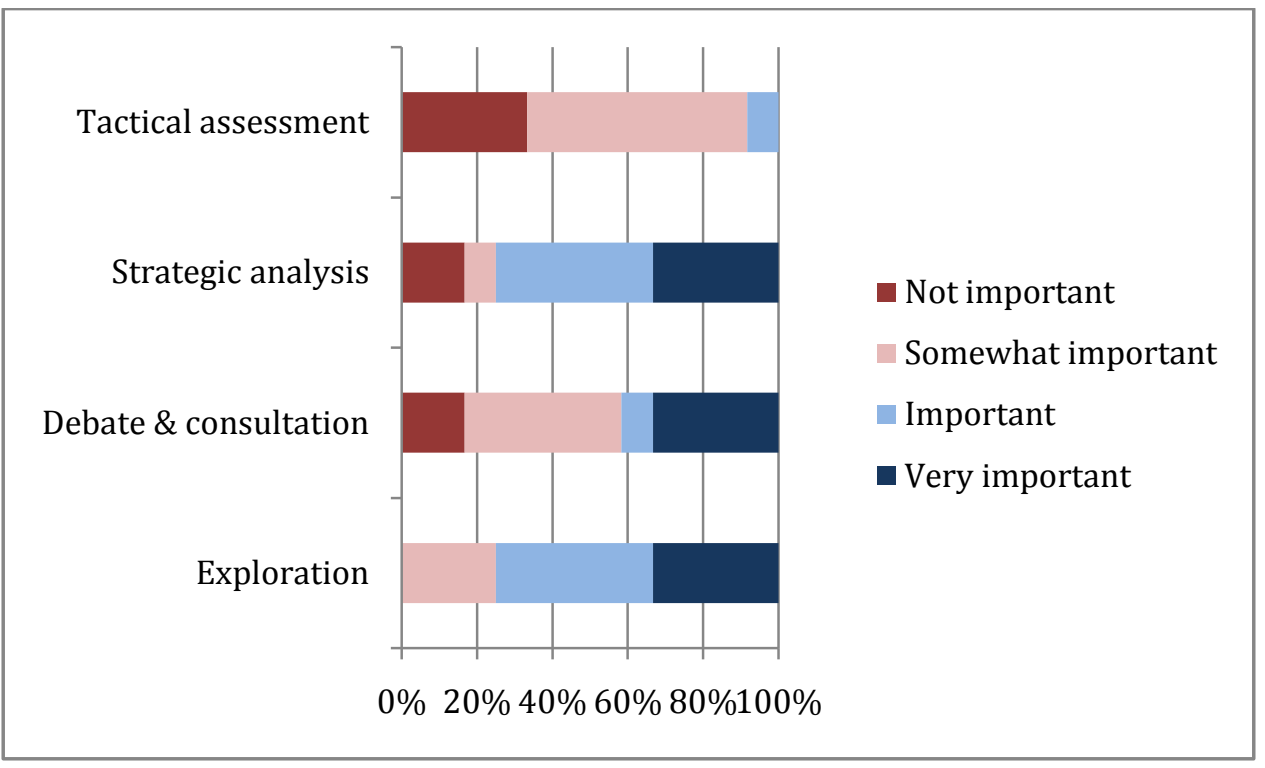

Fig. 1: Survey results for which type of use a LUTI could be helpful.

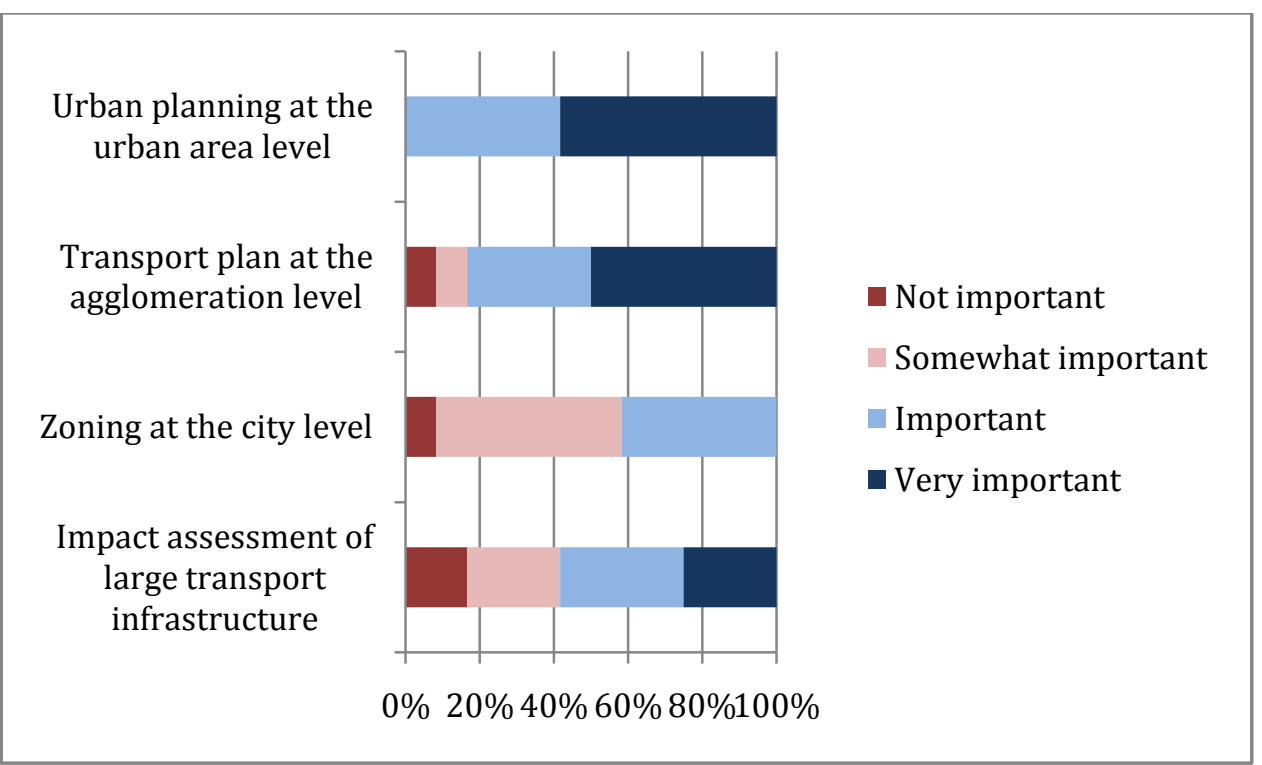

Fig. 2: Survey results for the type of document a LUTI could help to define;

Even among identical end users, we observe very heterogeneous results concerning the impact assessment of transport infrastructure (a document which refers to a tactical use of the model, including a cost benefit analysis). This reflects indecision between a tactical use and a strategic use, yet identified as more relevant in figure 1.

Another interesting aspect of LUTIs, prior to policy design and not often considered, should be mentioned. LUTI modeling can help team up transport and land use planning communities. It can help to connect the two visions before entering the steps of policy design. The simple fact that a LUTI asks for data from many different domains is a way to improve communication and common 
knowledge of a team in a planning agency. This is a lesson from our own implementations of LUTI models. For an actor like a transport authority, cooperating around a LUTI can also be a practical approach to better understand urban dynamics and to take into account the long-run effects. Generally speaking, LUTIs are a good tool for improving integration between transport and land use policies, an issue constantly discussed and pursued by research and practitioners.

Now that we have clarified the different expectations about LUTIs, we must evaluate to what extent they are used in practice to inform planning strategies.

\section{What are the major obstacles to LUTIs use? A need for more bottom-up approaches}

What prevent LUTIs from being widely used by local authorities? Do current LUTIs really answer the questions and practical issues local planning agencies are faced with on a daily basis? And are current LUTIs suitable with respect to their constraints and limitations? In this section, we use the data we have acquired during the fieldwork in addition to the review of the literature presented here to propose a framework and to elaborate ideas and propositions.

The main obstacles associated with these issues are threefold. First, it is difficult to match rather generic models with very specific and varied end users questions. Secondly, it is costly and challenging to implement and use a LUTI (capacity obstacles). Finally, there is no guarantee that the results of a dedicated LUTI will have any impact on the policy design (decision making obstacles).

\subsection{Matching with end user expectations}

A key idea is that one can only ask a numerical model questions it was created for. Even with the progress in computer sciences (language, algorithm) and technology (computational power), the numerical problems derived from urban systems are very complex, and we are forced to simplify reality in order to be able to solve them. As discussed by Shiftan and Ben-Akiva (2011) in the context of activity-based travel demand modeling, the proposed approaches must be able to capture "key behavioural aspects and policy sensitivities while remaining practical with reasonable requirements of computational resources". Without precise questions, it is not possible to reduce the model in the right direction.

However, our experience shows that end users usually do not know how to precisely formulate the 
questions they want to answer with the model. Indeed, they are not LUTIs experts and planning questions are very vast. Nevertheless, modelers need these questions in order to develop a relevant model. It is difficult to solve this knot not only because it is costly for end users to become familiar with LUTIs and to understand the questions they can address, but also because it is costly for researchers or consultants to develop different model versions in an iterative co-building process.

The interviews reveal that it is very difficult for non-specialists of LUTIs to follow the progress of science and to judge the value of a model. Workshops organized at the national level in France are not sufficient to really understand to what extent these models are operational, and to identify the pros and cons of each model (black box effect, complexity of these tools and a research dynamic that "adds complexity to complexity", and the difficulty for researchers or developers to underline the weaknesses and limitations of their model). To overcome these difficulties, workshops should go further in practical details and reveal the actual level of maturity of LUTIs. Since it is crucial to adapt the LUTIs to current key issues that correspond to real and practical needs of potential end users in a very pragmatic way, they should also help gather end users expectations. The development of userfriendly human-machine interfaces between modelers and end users is also very important, e.g. VIBAT project offers interactive simulation tools like TC-Sim ${ }^{11}$, dedicated to supporting a collaborative planning approach.

\subsection{Capacity obstacles: local resource limitation vs. growing complexity}

Capacity limitations are strong binding constraints because of the growing complexity of LUTIs. This gives rise to the simple/complex model debate. The scientific community tends towards more and more complexity (Timmermans and Arentze, 2011) and this is favored by an increasing computational power (lacono et al., 2008), see Fig. 3. The academic logic searches innovation and sophistication of modeling tools, and the usability is probably not the main objective of researchers. Moreover Wegener (2011, p. 4) observes with Lee (1973) that the "urban modeling community largely retreated to academia". This approach focusing on tool development can be identified as "top-down".

As illustrated in Fig. 3, adding complexity has its limits, and simpler and easier modeling is still necessary (Hardy, 2011; Klosterman, 2012; Brömmelstroet and Bertolini, 2008; May et al., 2008). A LUTI model should be simple, not to be confused with simplistic.

\footnotetext{
${ }^{11}$ See http://www.vibat.org/vibat Idn/tcsim.shtml
} 


\section{Drivers}

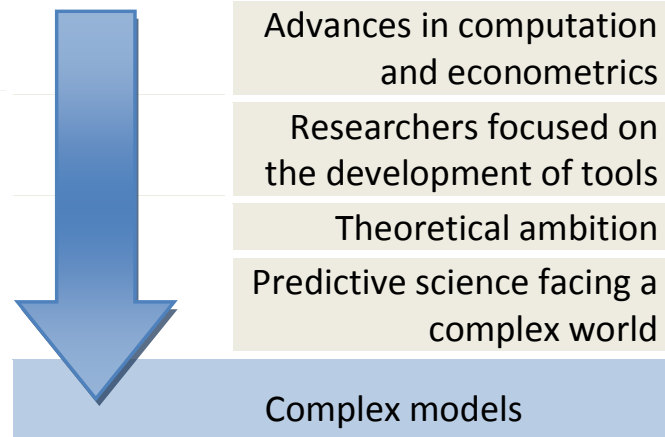

1. Complexity $\rightarrow$ more hypotheses, with a strong impact on results, not always discussed.

2. Complexity can seem neutral (sophistication let think there is no modeling choices), but no models are neutral.

3. Possible development of "non essential" complexity.

4. Marginal cost to get micro data sometimes bigger than value added.

5. Not focused on the integration into the planning process.
Epistemology

related issues

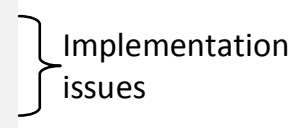
\} Decision help

Fig. 3: A move towards more complexity - drivers and limits of complexity; Illustration based on (Klosterman, 2012; Hardy, 2011; Wagner and Wegener, 2007)

As depicted in Fig. 4, model complexity is a combination of theoretical complexity of a tool and implementation design. Concerning implementation of a model, one element allowing to reduce (at least partly) the complexity is the development of specific tools and methodologies to facilitate the calibration and validation processes. In any case, it is essential to better understand the level of the required complexity and to adapt a model according to the final objectives. A model also needs to be adapted to the local capacity. Complexity should therefore be understood as the confrontation between modeling and local capacity.

In this context, it makes sense to oppose the "top-down" approach, focused on tool development (by itself), to the "bottom-up" approach which focuses on operational planning needs and limitations, and the way to fulfill them, as illustrated by Hardy (2011), Klosterman (2012), May et al. (2008) and Brömmelstroet and Bertolini (2008), and where more attention is paid to simplifying models. This bottom-up approach is also illustrated in Vickerman (2008), which stresses the need for a better understanding between policy makers and modelers. Bottom-up approaches have so far been neglected even though being essential to ensure pragmatic and operational LUTIs, since they could 
allow to better fit to end users capacity and demands.

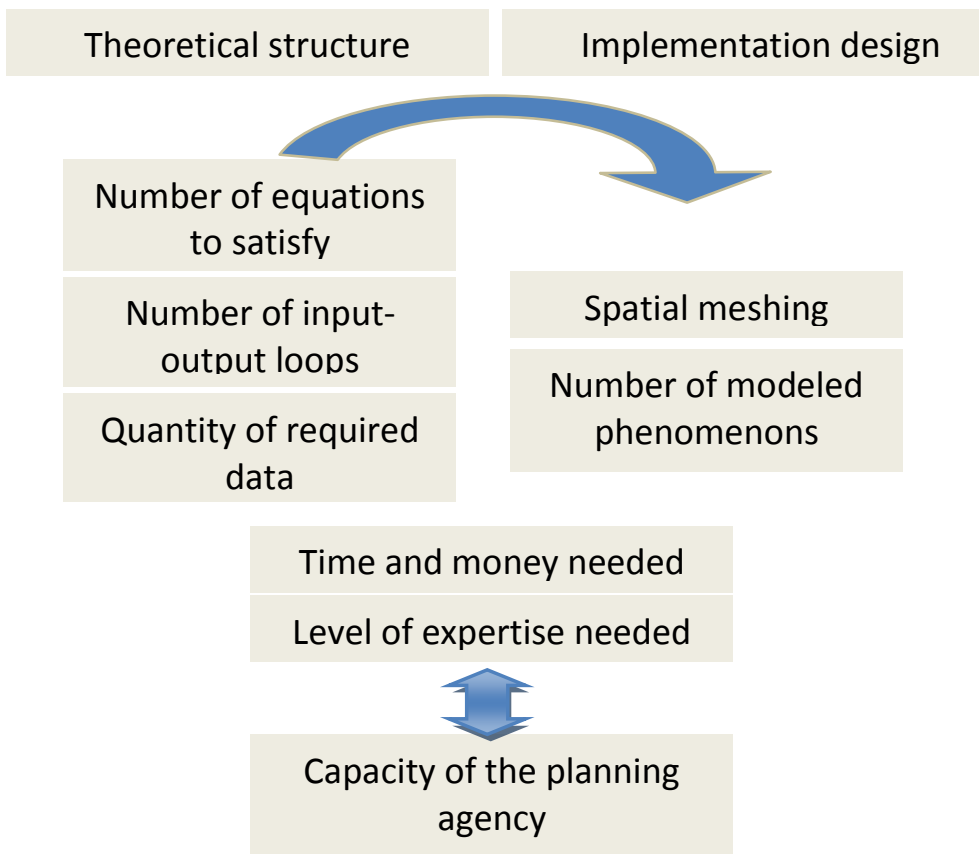

Fig. 4: A representation of complexity; illustration based on Klosterman (2012), Hardy (2011)

In France, based on both our experience and the survey, we observe that one of the main obstacles of LUTI implementation comes from the resource limitation of local agencies in terms of time, money and expertise. LUTIs are very demanding in data collection, harmonization and preparation, and require modeling and econometric capabilities. Appropriated methodologies and quantitative modeling skills are not that much standardized and disseminated. Any implementation of a LUTI requires a very time consuming step of calibration. This process can take several months, as our experience has shown. Clearly the time required to calibrate is neither compatible with the current constraints of consulting firms nor with the resource restriction of local agencies.

\subsection{Decision making obstacles}

Even assuming that capacity obstacles can be overcome and that a LUTI can be built to serve in a decision making process, there is no guarantee that its outcome will be of any use. In this section, we analyze the difficulty to understand the model outputs before using them for decision making.

\subsubsection{Black box effect}

The "black box" problem, based on literature and our own experience, implies the difficulty to 
promote results of LUTI models among practitioners who have no direct control over the implementation of these models, because they do not trust what they can't understand. Moreover, as revealed by the interviews, there is sometimes not only the difficulty of understanding the way a model works but more fundamentally understanding what a model is. As Timmermans (2003) and Vickerman (2008) stated, there is a paradox between the search for more modeling complexity, in order to represent the complexity of urban systems, and the black box effect; a paradox from which it is difficult to escape. Waddell (2011) observes a conflict between transparency (which needs simplicity) and validity (which needs complexity). This clearly brings us back to the simple/complex trade off.

Interestingly, another way to look at this question of black box effect is from the philosophy of the model. Common experience tends to show that micro simulation (like Urbansim) or activity-based models (like Albatross) are closer to intuition than more classical tools (like 4-steps or Tranus for example), which rely on a more important abstraction. They are easier to understand for nonmodelers (see Timmermans and Arentze, 2011, for an illustration). We can distinguish two dimensions in understanding of a model: the global understanding of the model rationale, its architecture and functioning, and the ability to identify causal links between inputs and outputs. Some models can be easy to understand in the first dimension and more complex in the second one. To have an impact on practical planning, a tool needs to be understood in both dimensions: because various persons with different profiles and responsibilities are involved (decision maker interested in the philosophy, technician interested in causal effects) and because these two dimensions play a role at different steps of the process (first try with the model, scenario analysis, etc.).

The survey reveals that the black box effect issue is very considerable: among respondents, 9 considered it very important and 1 important. Moreover several lessons can be learned from the answers to the open-ended question on how to solve this problem:

- To clearly distinguish input data, calibration data, parameters and outputs.

- To identify and explain the key inputs for the model results.

- To share and validate every step of the development with all partners.

- To use these models only for very prospective and strategic analyses, mainly for pedagogy. Similarly, we think that it would be very beneficial to develop better guidelines for the implementation of the models and to disseminate this knowledge through training and teaching. All this would clearly help circumvent the dilemma "complex - representative" versus "simple transparent". 
Furthermore, the fact that modeling tools are not used in the planning process is explained very differently by planners and modelers. Modelers would often consider that models are not complex enough to represent reality whereas planners may not see the interest of having details and precisions through a numerical tool and would underline the need for stakeholder involvement (Brommelstroet and Bertolini 2008). For example, Timmermans and Arentze (2011) consider that the key point is to help decision makers understand the mechanism of the urban system by capturing the complex interrelationships of the problem under investigation. To do so, they call for more complexity in order to avoid the risk of bad decisions. For Mostashari and Sussman (2005), a more complex model or a better mathematical validation will not help to include modeling results in decision making, but rather stakeholder involvement will.

It is not the purpose of this paper to conclude on the pros and cons of complexity in urban modeling. What we can say from our analysis is that in a theoretical world, complex models are promising and interesting, but in our very constrained world, planning agency capacities are limited. Our study sheds light on the needs for more bottom-up methods, which requires co-construction with endusers. This asks for resources. A complex model will draw most of the resources for its implementation, limiting the capacity to set up these collaborative procedures. Trade-offs must be made. For a broader diffusion of LUTIs in planning processes, academics should emphasize more bottom-up approaches.

Interviews reveal that a key issue for many actors (notably in France, for the Ministry of Ecology, Sustainable Development and Energy) is whether it is possible to provide rational and science-based tools to support specifically decision-making. This is especially the case through cost-benefits analysis, in a context where this method has progressively lost its importance in the decision making process. From this perspective, the question for LUTI models is the following: do LUTIs help decision making in a wider socio-economic evaluation, by providing clear, understandable and convincing results useful in a cost-benefit analysis? Can they provide sufficient value added that would compensate for additional complexity and black box effects they may generate?

\subsubsection{How reliable are LUTI models? Obstacles in terms of calibration and validation $^{12}$}

\footnotetext{
${ }^{12}$ It is worth noting that this section does not rely on the survey and interviews used in the rest of the article, but rather on our own experience, debates within our research consortium and the literature.
} 
The low level of use and impact on decision making of LUTIs can also come from a lack of confidence in their results, partly related to the absence of a clear and consensual definition of calibration and validation in the literature (Bonnel et al., 2014). We define calibration and validation as follows (Bonnel et al., 2014):

- Calibration refers to the determination of parameters values

- Estimation refers to the use of specific statistical or econometric methods and calibration is a process overarching the estimation process.

- Validation refers to testing the predictive power of the method using out-of-sample data.

- A calibration ensures that the model is acceptable; a validation is always partial since a test can only invalidate a model.

LUTIs, as any numerical models, are inherently uncertain as they rely on both theoretical assumptions and data quality. There is no physical law ensuring reliability of models. Consequently, there are neither neutral models (Klosterman, 2012) nor objective rules to state that one specification is better than another (Sterman, 2000; Pfaffenbichler et al., 2008). Thus there is no absolute calibration or validation, both for simple and complex models. Moreover, new models cannot "meet all basic scientific criteria" and be used for theory testing, but they can provide "robust but contingent knowledge" (Batty, 2009, p. 6). Calibration and validation should be seen in this respect.

Calibration and validation procedures lead to theoretical, methodological, and practical difficulties (time, resource, data). The practical difficulties are one of the main obstacles of LUTI use. Moreover these procedures need to be understandable by end users in order to produce confidence in the model. To ensure the relevance of the model in line with its practical objectives, the criteria used to calibrate and validate the model must be based on relevant indicators defined by end users. Model testing should be specific to the type of expected use, see figure 5 .

Wegener (2013) also observes that models should be adapted to new contexts for planning (climate change and increasing energy prices). Models should less be based on extrapolation of past trends and observed behaviors, and therefore should less rely on statistical calibration. A plausibility analysis would be more meaningful. This is directly related to the need to conduct a sensitivity analysis on top of a historical validation.

\begin{tabular}{|l|llll|}
\cline { 2 - 5 } \multicolumn{1}{c|}{} & \multicolumn{1}{c|}{ Exploration } & Debate & Strategic analysis & Tactical assessment \\
\hline $\begin{array}{l}\text { Value added of } \\
\text { LUTI modeling }\end{array}$ & $\begin{array}{l}\text { Interactive support } \\
\text { for prospective }\end{array}$ & $\begin{array}{l}\text { Neutral/ unbiased } \\
\text { support }\end{array}$ & $\begin{array}{l}\text { Support for policy } \\
\text { analysis and ranking of }\end{array}$ & $\begin{array}{l}\text { A lot of indicators with } \\
\text { precise results }\end{array}$ \\
\hline
\end{tabular}




\begin{tabular}{|l|llll|}
\hline & studies & measures & \\
\hline $\begin{array}{l}\text { Main } \\
\text { requirement } \\
\text { for the model }\end{array}$ & $\begin{array}{l}\text { Easy and flexible to } \\
\text { use in prospective } \\
\text { studies }\end{array}$ & $\begin{array}{l}\text { Understandable by } \\
\text { stakeholders }\end{array}$ & $\begin{array}{l}\text { Representation of key } \\
\text { mechanisms }\end{array}$ & $\begin{array}{l}\text { Comprehensive } \\
\text { representation }\end{array}$ \\
\hline $\begin{array}{l}\text { Requirement } \\
\text { for calibration/ } \\
\text { validation }\end{array}$ & $\begin{array}{l}\text { Aggregated } \\
\text { sensitivity tests to } \\
\text { show the reliability } \\
\text { of prospective } \\
\text { studies }\end{array}$ & $\begin{array}{l}\text { Test to ensure trust } \\
\text { of the different } \\
\text { stakeholders }\end{array}$ & $\begin{array}{l}\text { More precise tests to } \\
\text { ensure that the } \\
\text { selected indicators are } \\
\text { reliable }\end{array}$ & $\begin{array}{l}\text { Tests at smaller scale } \\
\text { of the model }\end{array}$ \\
\hline
\end{tabular}

Fig. 5: Calibration and validation requirements depending on the type of use (elaborated by authors)

Historical validation is generally considered a key step for validation in the research community. To be able to simulate a past development is a clue that the model is working correctly, but it is not a guarantee for prospective modeling. Waddell $(2011$, p. 7) speaks about "behavioral validity" to include more "intuitive understandings" of the model. Compared to "hard science" modeling, socioeconomic models face difficulties in collecting (sufficient) data and replicating results. In a context of low resources, developing a sensitivity analysis is particularly interesting (Wenban-Smith et al., 2009; Franklin et al., 2002; Duthie et al., 2010). It is likely that sensitivity tests using scenarios increase both the scientific value of the modeling process and the understanding of the modeling process by the end user/ practitioner. In our survey, answers show that sensitivity tests appear to be decisive to validate the model and increase transparency. We think that sensitivity analysis has several benefits:

- To improve and validate the model. As a way to validate the model it improves the quality of modeling. There can be back and forth work between the calibration stage and the sensitivity tests.

- To increase involvement of stakeholders. Via the sensitivity analysis, the end users can easily participate by proposing tests and scenarios and expressing expectations about the test outputs. By taking part in the design and validation phase of the model one can guarantee better ownership of the model by the stakeholders.

- To overcome the black box effect. It increases the ability of the end users to understand the processes. Tests should be chosen to help end users understand the most complex links and interactions in the model. This improved understanding naturally increases the confidence of end users in the model.

\section{Conclusion.}

In this article, we propose another perspective for LUTI modeling that is based on user expectation rather than model specifications. In our analysis of the French case and the literature, we have 
identified the obstacles to a wide use of LUTIs. We have also shown the conditions for fostering LUTIs' practical use in planning. The survey and interviews have been a way to better define the possible use of LUTIs. Its seems that an opportunity exists for LUTIs, but also several obstacles: transport models are already considered as heavy and complex to use, whereas LUTI imply even more complexity and validation needs while evoking a black box effect.

Considering not primarily theoretical development and features, but the actual use of LUTI models, it appears that end users have a critical role to play. They have to guide researchers to adapt their tools to the needs and the constraints/limitations of the end users. The key idea is to reintegrate LUTI modeling as a key component into the planning process. LUTIs are at the interface of qualitative and quantitative standpoints. Since the context is very constrained in terms of resources and LUTI models are costly, and because the impact of modeling on the decision making process is not straightforward, it is mandatory to be very precise about the needs of end users in order to specify LUTI modeling requirements. Top-down approaches have been useful to provide different structures of LUTIs, but today we need more bottom-up approaches to make LUTIs more popular.

In order to overcome these difficulties and to move from top-down approaches to more bottom-up approaches, we have identified the following priorities:

- To focus on the practical conditions of LUTI implementation and to identify the needs of end users.

- To set up specific interaction procedures between end users and modelers, using visualization tools which favor the integration of LUTIs into the planning process (this could be done via a better association of PSS approaches and LUTI modeling).

- To clarify and develop:

○ calibration tools,

○ validation methodologies,

○ and a framework for sensitivity tests

$\ldots$ and to involve end users in all these stages.

- To develop better implementation guidelines for LUTI models.

- To disseminate knowledge through training and teaching.

Acknowledgements:

The authors wish to thank the ANR research program and the EcosNord program for funding this research. The authors also wish to thank Ifsttar, Inria and Iddri for supporting this research, and the 
other researchers of the CITIES consortium for the preparation of the article.

\section{References:}

- Anas, A. (2013) 'A response to the guest editorial: economics as the science for urban modeling', Environment and Planning B: Planning and Design 40(6) 955 - 958

- Banister, D., Hickman, R. (2013) Transport Futures: Thinking the unthinkable Transport Policy (29) 283-293

- Batty, M. (1979) 'Progress, success and failure in urban modeling', Environment \& Planning A, 11(8) 863-878.

- Batty, M. (2009) 'Urban modeling'. In: R. Kitchin and N. Thrift (eds.), International Encyclopedia of Human Geography, Elsevier Science

- Bonnafous, A., Crozet ,Y., Mercier, A., Ovtracht N., Péguy P.-Y., Puech F. (2011) 'MOSART et le projet PLAINSUDD : une plate-forme de modélisation et simulation de l'accessibilité pour l'aide à la décision et l'aménagement du territoire'. In Modéliser la ville : formes urbaines et politiques de transport sous la direction de J.-P. Antoni, Ed. Economica, pp. 186-210.

- Bonnel, P., Coulombel, N., Prados, E., Sturm, P., Arnaud, E., Boittin, C., Bouzouina, L., Cabrera Delgado, J., Capelle, T., Delons, J., Gilquin, G., Hilaire, V., Lapparent, M.(de), Nguyen-Luong, D., Nicolas, J.-P., Saujot, M., Tschirhard, A., Vidard. A. (2014) 'A survey on the calibration and validation of integrated land use and transportation models'. In Proc. of SYMPOSIUM "Toward integrated modeling of urban systems, 15-17 Oct. 2014, Lyon, France;

- Brömmelstroet, M.T., Bertolini, L. (2008) 'Developing land use and transport PSS: Meaningful information through a dialogue between modelers and planners', Transport Policy 15 (4) 251259

- Delons, J., Coulombel, N., and Leurent F., (2008) PIRANDELLO an integrated transport and landuse model for the Paris area. Preprint: https://hal.archives-ouvertes.fr/hal-00319087

- Duthie, J., Voruganti, A., Kockelman, K.M., and Waller, S.T. (2010) 'Highway Improvement Project Rankings due to Uncertain Model Inputs: Application of Traditional Transportation and Land Use Models', Journal of Urban Planning and Development 136 (4) 294-302

- Ewing, R. Bartholomew, K. (2009) 'Comparing Land Use Forecasting Methods', Journal of the American Planning Association, 75 (3) 343-357

- Feldman, O., Davies, J., Simmonds, D., Young, D., Richmond, E., Valero, J. (2009) ‘An Integrated System of Transport and Land-Use Models for Auckland and its Application'. Paper presented to 
the 11th International Conference on Computers in Urban Planning and Urban Management (CUPUM), Hong Kong, 16-18 June 2009.

- Franklin, J.P., Waddel, P., Britting, J. (2002) 'Sensitivity analysis approach for an integrated land development \& travel demand modeling system'. Paper for presentation at the ACSP 44th Annual Conference Baltimore, MD, November 21-24, 2002

- Gayda, S., Haag, G., Besussi, E., Lautso, K., Noël, C., Martino, A., Moilanen, P., Dormois, R. (2005) 'Sprawling Cities And TransporT: from Evaluation to Recommendations: SCATTER'. Project funded by the European Commission under the « Energy, Environment and Sustainable Development Programme » of the 5th Framework Programme

- Gudmundsson, H. (2011) 'Analysing Models as a Knowledge Technology in Transport Planning.' Transport Reviews, Volume 31 (2) 145-159

- Hardy, M. (2011) 'Simplified integrated transportation and land use modeling to support metropolitan planning decisions: an application and assessment'. Ph.D thesis, George Mason University

- Hunt J.D., Kriger D.S., and Miller E.J. (2005) 'Current operational urban land-use-transport modeling frameworks: A review', Transport Reviews, 25 (3) $329-376$

- Hunt, J.D., Johnston, R.A., Abraham, JE., Rodier, C.J., Garry, G., Putman, S.H., de la Barra, T. (2001) 'Comparisons from the Sacramento Model Tested', Transportation Research Record: Journal of the Transportation Research Board, Volume 1780, 53-63

- lacono M., Levinson D., El-Geneidy A. (2008) 'Models of Transportation and Land Use Change: A Guide to the Territory', Journal of Planning Literature, 22(4) 323-340

- Jin, Y., Wegener, M. (2013) 'Beyond equilibrium', Environment and Planning B: Planning and Design 40(6) $951-954$

- Klosterman, R.E. (1994a) 'An Introduction to the Literature on Large-Scale Urban Models, Journal of the American Planning Association, 60(1) 41-44

- Klosterman, R.E. (1994b) 'Large-Scale Urban Models Retrospect and Prospect', Journal of the American Planning Association, 60(1) 3-6

- Klosterman, R.E. (2001) 'Planning support systems: a new perspective on computer aided planning', In: Brail, R.K., Klosterman, R.E. (Eds.), Planning Support Systems: Integrating Geographical Information Systems, Models and Visualization Tools. ESRI, New Brunswick, pp. 123.

- Klosterman, R.E. (2012) 'Commentary: Simple and complex model', Environment and Planning B: Planning and Design,39(1) 1-6 
- $\quad$ Lautso, K., Spiekermann, K., Wegener, M., Sheppard, I., Steadman, P., Martino, A., Domingo, R., Gayda, S. (2004) 'Propolis: Planning and Research of Policies for Land Use and Transport for Increasing Urban Sustainability', Final Report, Project Funded by the European Commission under the Energy, Environment and Sustainable Development Thematic Programme, February 2004

- Lee, D. B. (1973) 'Requiem for Large-Scale Models', Journal of the American Institute of Planners, 39(1) 163-78.

- Lee, D.B. (1994) 'Retrospective on large-scale urban models', Journal of the American Planning Association, 60 (1) 35-40.

- Lee, D.J.H. (2009) TMA/MPO Modeling Activity Survey, Fredericksburg Area Metropolitan Planning Organization.

- May, A.D., Page, M., Hull, A. (2008) 'Developing a set of decision-support tools for sustainable urban transport in the UK', Transport Policy, 15 (6) 328-340

- Mostashari, A., Sussman, J. (2005) 'Stakeholder-Assisted Modeling and Policy Design Process for Environmental Decision-Making', Journal of Environmental Assessment Policy \& Management, $7(3)$ 355-386.

- Nguyen-Luong, D., (2012) 'Les modèles transport-urbanisme : de la théorie à la pratique', Transports, 474(2) 14-19

- Nguyen-Luong, D. (2008), 'Projet SIMAURIF (SIMulation de l'interAction Urbanisation transports en Région Ile de France): Perfectionnement et valorisation', Rapport pour le PREDIT, Juillet 2008

- Nicolas, J.-P., Bonnel, P., Cabrera, J., Godinot, C., Homocianu, M., Routhier, J.-L., Toilier, F., Zuccarello, P. (2009) 'Simuler les mobilités pour une agglomération durable'. LET, Final Report. 211 p.

- Nilsson, M., Jordan, A., Turnpenny, J., Hertin, J., Nykvist, B., Russel, D. (2008) 'The use and nonuse of policy appraisal tools in public policy making: an analysis of three European countries and the European Union', Policy Sciences, 41(4) 335-355

- Pfaffenbichler, P., Emberger, G., Shepherd, S. (2008), 'The integrated dynamic land use and transport model MARS', Networks and Spatial Economics. DOI 10.1007/s11067-007-9050-7

- Sager, T., Ravlum, I.A. (2005), 'The Political Relevance of Planners' Analysis: The Case of a Parliamentary Standing Committee', Planning Theory, 4(1) 33-65 
- Saujot, M. (2013), Economic analysis and prospective modeling to plan low carbon cities. The case of Grenoble using TRANUS+ model. Available from: Pastel database http://pastel.archivesouvertes.fr/pastel-00982385

- Shiftan, Y., Ben-Akiva, M. (2011), 'A practical policy-sensitive, activity-based, travel-demand model', Annals of Regional Science, 47(3) 517-541

- Silva, E., Wu, N. (2012) 'Surveying Models in Urban Land Studies', Journal of Planning Literature, 27(2) 139-152

- Simmonds D., Echenique M. et al. Bates J. (1999) Review of Land-Use/ Transport Interaction Models. DETR, 72p. http://www.davidsimmonds.com/files/Review-of-Land-Use-TransportInteraction-Models.pdf

- Simmonds, D.C., Feldman, O. (2007) 'Advances in integrated urban/regional land-use/transport modeling using the DELTA package', Paper presented to the World Conference on Transport Research 2007, June 24-28, University of California, Berkeley.

- Sterman, J.D. (2000) Business Dynamics -Systems Thinking and modeling of a complex world. McGraw-Hill Higher Education

- Still, B.G., May, A.D., Bristow, A.L. (1999) 'The assessment of transport impacts on land use: practical uses in strategic planning', Transport Policy 6 (2) 83-98

- Sustaincity (2013) 'Microsimulation, land use and transportation models for more sustainable cities in Europe: WP2 - State of the art', European Policy Brief, European Research Area.

- Timmermans, H. (2003) 'The Saga of Integrated Land Use-Transport Modeling: How Many More Dreams Before We Wake Up?', Conference keynote speaker, 10th International Conference on Travel Behaviour Research Lucerne, 10-15. August 2003

- Timmermans, H., Arentze, T.A. (2011) 'Transport Models and Urban Planning Practice: Experiences with Albatross', Transport Reviews: A Transnational Transdisciplinary Journal, 31(2) 199-207

- Vecchione, E. (2012) 'Deliberating beyond evidence: lessons from Integrated Assessment Modeling', Paper prepared for the ISEE Conference, Rio de Janeiro, Brazil, 16-19 June 2012.

- Vickerman, R. (2008) 'Models in policy and policy in models: integrating decision making', Chapter 12 in M Ben-Akiva, H Meersman and E Van de Voorde (Eds.): Recent Developments in Transport Modelling: Lessons for the Freight Sector. Emerald, Bingley, 2008

- Vonk, G., Geertman, S., Schot, P. (2005) 'Bottlenecks blocking widespread usage of planning support Systems', Environment and Planning A, 37(5) 909- 924 
- Waddell, P. (2011) 'Integrated land use and transportation planning and modeling: addressing challenges in research and practice', Transport Reviews, 31(2)209-229

- Wagner, P. Wegener, M. (2007) 'Urban land use, transport and environment models, experiences with an integrated microscopic approach', Disp, 170(3) 46-56

- Wegener, M., (1994) 'Operational urban models: State of the art'. Journal of the American Planning Association, 60 (1), 17-29

- Wegener, M. (2004) 'Overview of land use transport models', Chapter 9 in David A. Hensher and Kenneth Button (Eds.): Transport Geography and Spatial Systems. Handbook 5 of the Handbook in Transport. Pergamon/Elsevier Science, Kidlington, UK, 2004, 127-146.

- Wegener, M. (2011) 'From macro to micro-how much micro is too much?' Transport Reviews, 31(2) 161-177.

- Wegener, M. (2013) 'The future of mobility in cities: Challenges for urban modeling', Transport Policy, 29 (2013) 275-282, doi:10.1016/j.tranpol.2012.07.004

- Wenban-Smith, A., Van Vuren, T., MacDonald, M. (2009) 'Using Transport Models in Spatial Planning: Issues from a review of the London Land Use/Transport Interaction Model'. Association for European Transport and contributors, 2009 


\section{Appendices}

\begin{tabular}{|c|c|c|}
\hline \multicolumn{2}{|c|}{ Foreword } & $\begin{array}{l}\text { We first explain the goal of our project, then we briefly describe LUTI models and give a short } \\
\text { example of an application. }\end{array}$ \\
\hline \multicolumn{2}{|c|}{ Guidelines } & $\begin{array}{l}\text { We assume that modeling is linked to political demand and we ask the respondent to answer } \\
\text { considering the most relevant practice in their opinion and not considering the political } \\
\text { demand. }\end{array}$ \\
\hline Q1 & \multicolumn{2}{|r|}{ Do you use a transport model? If yes, is it for prospective studies or tactical analysis? } \\
\hline Q2 & \multicolumn{2}{|r|}{ To what extent are you satisfied of your transport model? } \\
\hline Q3 & \multicolumn{2}{|r|}{ To what extent are you autonomous in transport modeling? Do you need consultant firms? } \\
\hline Q4 & \multicolumn{2}{|r|}{ For a given study, do you outsource or can you "run" the model internally? } \\
\hline Q5 & \multicolumn{2}{|r|}{$\begin{array}{l}\text { What limits do you see in your transport model? 1) Complexity 2) Heavy to use 3) Absence of land use } \\
\text { dimension 4) hard to use for prospective studies 5) other }\end{array}$} \\
\hline Q6 & \multicolumn{2}{|r|}{$\begin{array}{l}\text { Indicate how important it is to consider land use policies and transport policies in an integrated } \\
\text { manner: 1) not important 2) moderately important 3) important 4) very important }\end{array}$} \\
\hline Q7 & \multicolumn{2}{|r|}{$\begin{array}{l}\text { Besides other types of analysis, indicate how important modeling tools are to evaluate such policies } \\
\text { and to help define them: (same as precedent). }\end{array}$} \\
\hline Q8 & \multicolumn{2}{|r|}{$\begin{array}{l}\text { For prospective studies, at what scale should we mainly take into account these policies? 1) District 2) } \\
\text { Corridor 3) City 4) Urban area (city + suburbs) 5) Region }\end{array}$} \\
\hline Q9 & \multicolumn{2}{|r|}{ With what time horizon? 10 years; $20-30$ years; 50 years } \\
\hline Q10 & \multicolumn{2}{|r|}{$\begin{array}{l}\text { LUTIs are essential: 1) to explore the planning possibilities 2) to debate scenarios 3) for strategic } \\
\text { analysis 4) for tactical assessment }\end{array}$} \\
\hline Q11 & \multicolumn{2}{|r|}{$\begin{array}{l}\text { At what scale results need to be produced for each precedent task? 1) Plot 2) District 3) City 4) a } \\
\text { merging of cities }\end{array}$} \\
\hline Q12 & \multicolumn{2}{|r|}{$\begin{array}{l}\text { For which document would LUTIs be the most useful? 1) Impact assessment of large transport } \\
\text { infrastructures 2) zoning at the city level 3) transport planning at the urban area level 4) urban } \\
\text { planning at the urban area level }\end{array}$} \\
\hline Q13 & \multicolumn{2}{|r|}{$\begin{array}{l}\text { Do you agree with the following assertions (no, rather, yes): 1) a LUTI is useful to forecast future } \\
\text { urban development (long term) 2) a LUTI is useful to understand the complexity of urban systems 3) a } \\
\text { LUTI is useful to compare trends and scenarios but not for forecasting 4) transport modeling is already } \\
\text { sufficient, there is no need for more complexity with another modeling tool. }\end{array}$} \\
\hline Q14 & \multicolumn{2}{|r|}{$\begin{array}{l}\text { How to decide between a LUTI and your transport modeling tool? 1) Complementary use: tactical/ } \\
\text { strategic use 2) Replacement by the LUTI 3) Interoperability: outputs of the LUTI used for transport } \\
\text { modeling }\end{array}$} \\
\hline Q15 & \multicolumn{2}{|r|}{$\begin{array}{l}\text { Numerical models are often considered as black boxes because the end user has a limited } \\
\text { understanding of the calculus made by the model. To what extent is transparency important for you? }\end{array}$} \\
\hline
\end{tabular}




\begin{tabular}{|l|l|}
\hline Q16 & $\begin{array}{l}\text { How to escape the following dilemma: urban dynamics are very complex and require complex tools, } \\
\text { but complexity implies less transparency. In other words, how to improve transparency? }\end{array}$ \\
\hline Q17 & $\begin{array}{l}\text { Which indicators should be used for the calibration of a LUTI? 1) Households and job distribution 2) } \\
\text { Land price 3) Origin-destination matrix for home-work 4) Distance travelled at peak hour 5) Modal } \\
\text { share 6) Travel time and speed 7) Urban density 8) Others }\end{array}$ \\
\hline Q18 & $\begin{array}{l}\text { To what extent are these tests essential for validation? 1) Historical simulation 2) Sensitivity test } \\
\text { Q19 }\end{array}$ \\
$\begin{array}{l}\text { Do you agree with the following assertion? Sensitivity tests could improve my understanding of the } \\
\text { model and hence the transparency of the modeling tool. }\end{array}$ \\
\hline Q20 & \begin{tabular}{l} 
Free comments. \\
\hline
\end{tabular}
\end{tabular}

